\title{
Programme Integrating Courses Fighting to Get Engineers to Reflect on Non-technical Topics
}

\author{
Emma Riese \\ Division of Theoretical Computer Science \\ KTH Royal Institute of Technology \\ Stockholm, Sweden \\ riese@kth.se
}

Björn Hedin

Division of Media Technology and Interaction Design

KTH Royal Institute of Technology

Stockholm, Sweden

bjornh@kth.se

\author{
Olle Bälter \\ Division of Media Technology and Interaction Design \\ KTH Royal Institute of Technology \\ Stockholm, Sweden \\ ob1@kth.se \\ Viggo Kann \\ Division of Theoretical Computer Science \\ KTH Royal Institute of Technology \\ Stockholm, Sweden \\ viggo@kth.se
}

\begin{abstract}
Programme Integrating Courses (PICs) aim to tie students, teachers and courses in education programmes closer together. In this study, we investigate three PICs, as part of engineering programmes in computer science and media technology. The purpose of this study was to gain a deeper understanding of how students and mentors experience the PICs with a focus on the assessment and the relationship between students, and students and mentors. We used a mixed method approach, interviewed 22 students and 6 mentors, and sent out questionnaires to all 25 mentors and all students from two of the three courses $(630+470$ students). The results showed that the students and mentors appreciated the social aspects of the courses, getting to know each other and share experiences. However, some were uncomfortable reflecting upon the given non-technical topics. On a general level, the students stated that their mentors assessed their reflections correctly but they were sceptical towards being graded on a scale other than pass/fail.
\end{abstract}

\section{CCS CONCEPTS}

- Social and professional topics $\rightarrow$ Computational science and engineering education

\section{KEYWORDS}

Programme integrating course; assessment; engineering students; reflection; higher education

\section{ACM Reference format:}

Emma Riese, Olle Bälter, Björn Hedin and Viggo Kann. 2019. Programme Integrating Courses Fighting to Get Engineers to Reflect on Non-technical Topics. In Proceedings of 24rd Annual ACM Conference on Innovation and Technology in Computer Science Education (ITiCSE'19), fuly 15-17, Aberdeen,

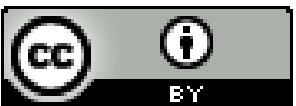

This work is licensed under a Creative Commons Attribution International 4.0 License. ITiCSE '19, Fuly 15-17, 2019, Aberdeen, Scotland, UK. (C) 2019 Copyright is held by the owner/author(s). ACM ISBN 978-1-4503-6301-3/19/07. http://dx.doi.org/10.1145/3304221.3319754
Scotland, UK. ACM, New York, NY, USA, 7 pages, https://doi.org/10.1145/3304221.3319754

\section{INTRODUCTION}

At universities that offer educational programmes where the courses are offered by different departments, with their own research and teaching traditions, students can perceive the programme as scattered and question the value of certain courses. This can lead to less motivated students with poorer results as a consequence. One way to include the students in a discussion about the programme and its content is in a Program Integrating Course (PIC). A PIC aims to tie courses in an education programme closer together by offering the programme's students time to reflect on taken courses and the relationship between them. This is carried out in smaller groups (10-18 students) together with a mentor, a teacher on the programme. In addition, the PICs would also include other topics to reflect upon, such as ways to handle procrastination and relation between the education, work and private life [11].

The PIC concept was developed ten years ago at KTH Royal Institute of Technology (KTH), Stockholm, Sweden [10] and has now spread to other universities [12] and Computer Science institutions in both the UK and US are planning to introduce similar courses. The PICs at KTH have been evaluated repeatedly $[13,14,15]$ with positive results and have also been a vessel for the development of walking seminars [5]. These studies have shown that PICs can be a powerful instrument to improve what the students get out of their studies and also to get participating teachers more familiar with the students' study situation. However, we see that the PICs fail to reach some students. If we can better understand why, we can hopefully improve the design of the courses so that they become rewarding for virtually all participants. Previous studies of PICs have relied solely on questionnaires, but in this study, we have also included interviews in order to achieve a more nuanced picture both from the students and the mentors with a focus on three questions:

- Which is the perceived purpose with the course? 
- How is the assessment in these programme integrating courses perceived?

- How is the relationship between students, and students and mentors perceived?

\section{RELATED RESEARCH}

Academic success is linked to students' use of self-regulating learning strategies, such as self-evaluation, organization, seeking social assistance (peers, teacher, or other adults) and planning [21]. However, just telling students about such strategies is not sufficient. "Educators can pave the way by placing learning about learning on the agenda of their educational programs" [16], which can be done using reflection tasks. In a study of alumni of engineering education programmes, engineers in work life have difficulties finding relevance of the actual learning and studies within the engineering educational programmes. Looking back, they "view their education as compartmentalized or fragmented, and they lack a main thread in the educational programme" [18]. PICs are designed to address this, help the students to use selfregulating learning strategies and make them aware of how the different courses, knowledge areas and skills are linked together. A recent study shows that the students of the PICs have the same view of the competences that their education programmes should develop as the programme coordinator has [7].

When designing a course, constructive alignment [2] is a concept where the learning activities, the assessment and the learning outcomes are aligned. That is, the learning activities are created in such a way that, if undertaken, they will lead to a passed assessment and thereby to a learning outcome matching the intended learning outcomes. Constructive alignment can be applied with varying granularity: from learning modules, over courses to entire programmes.

The teacher-students relationship has been well studied and recognized as an important factor for success in school settings, but not studied to the same extent in higher education [8]. This can be explained by the fact that interactions between teachers and students tend to be fragmented and that the students are expected to be independent adults when reaching this level [8]. However, already in 1975, a theoretical model of student retention was presented and argued that those students who are integrated both socially and academically will persist and be successful in their studies [20]. There is also empirical evidence that the social relationships, between students and between students and faculty, have an impact on the students' sense of belonging and retention rate [19]. How much the faculty should care about and interact with their students, has on the other hand, shown to cause some disagreement [8]. For example, while some faculty experienced being part of student integration as beneficial and important, others experienced is as being unnecessary [17]. How teachers treat their students is a factor in successful teaching, but attributed to mutual trust and engagement rather than personality of the teachers [1]. There are, however, few studies that have been conducted on how faculty experience their interactions with students [8], something that will be further explored in this paper.

\section{RESEARCH SETTING}

In this paper, we study three different PICs at KTH, each mandatory within an educational programme. The three PICs are described as they were structured during the academic year 2017/2018, see Table 1 .

Table 1. Descriptions of the studied PICs

\begin{tabular}{|l|l|l|l|}
\hline Course & PIC1 & PIC2 & PIC3 \\
\hline Years & 3 & 3 & 2 \\
\hline Cycle & first & first & second \\
\hline $\begin{array}{l}\text { Part of Education } \\
\text { programme }\end{array}$ & $\begin{array}{l}\text { Media } \\
\text { Technology }\end{array}$ & $\begin{array}{l}\text { Computer Science } \\
\text { and Engineering }\end{array}$ & $\begin{array}{l}\text { Computer } \\
\text { Science }\end{array}$ \\
\hline Number of groups & 20 & 39 & 24 \\
\hline Mentors & 6 & 13 & 12 \\
\hline $\begin{array}{l}\text { Number of students } \\
\text { per group }\end{array}$ & $10-12$ & $12-14$ & $16-18$ \\
\hline Length of seminar & 80 minutes & 60-70 minutes & 50 minutes \\
\hline $\begin{array}{l}\text { Grading of seminar } \\
\text { activity }\end{array}$ & $\begin{array}{l}\text { yes, point } \\
\text { system }\end{array}$ & yes, two levels & no, pass/fail \\
\hline $\begin{array}{l}\text { Grading of reflection } \\
\text { documents }\end{array}$ & $\begin{array}{l}\text { yes, point } \\
\text { system }\end{array}$ & yes, two levels & no, pass/fail \\
\hline $\begin{array}{l}\text { Peer comments } \\
\text { yes, within the } \\
\text { group }\end{array}$ & no & $\begin{array}{l}\text { yes, within } \\
\text { the group }\end{array}$ \\
\hline
\end{tabular}

The students in each PIC are divided into seminars groups that consist of students from all years of the programme and one mentor, a teacher on the programme. All three courses are centered around four reflection seminars each year, with a dedicated topic, such as procrastination or ethics. Before each seminar, the students are asked to study the topic and write a reflection based on this and their own experiences. A 4-level reflection model developed by Kann and Magnell [15], based on Hatton and Smith [9], is used in PIC1 and PIC2. In all three PICS, the students also reflect upon recently taken courses. The reflection is shared to the group members including the mentor, who asynchronously discuss the texts online. The topic and the courses are then discussed further at a physical meeting, such as a walking seminar [5], where the group discusses the topic while walking in the woods behind campus.

In all three PICs the students' reflections and participation are assessed, but according to different systems. In PIC1, a point-based grading scheme is used, 7 points is given if everything is done as instructed and points are deducted, for example, if the assignment is handed in too late. In PIC2, the mentors grade both the submitted reflection and the seminar activity using a two level scale. In order to reach the highest grade for the reflection, the student has to submit a document fulfilling all stated criteria. For second and third year students, the criteria include reaching level 3 and 4 in the reflection model. To reach the highest grade for the seminar activity, the student has to be on time and be active during the seminar. In PIC3, the students are graded pass/fail on the reflection documents and on participation in the seminar.

\section{METHODOLOGY}

In this study, data was collected from late spring 2017 to early fall 2018, using both questionnaires and interviews with students 
and mentors. This mixed method [6] approach was chosen since we were interested in both the general perceptions and trends, but also getting a dataset that could further explain these experiences.

The interviews were conducted from spring to early fall 2018. Participation was voluntary and as a small token of appreciation, all interviewees were given a voucher for a cinema ticket. The interviews were conducted by the first author who had no previous experience from any of the studied courses, and is not a mentor nor course coordinator, to avoid conflict of interest. All interviewees agreed to have their interview recorded and to be part of the study. To protect the interviewees' privacy, names and another type of identifications are not presented in the results. The interviews were semi-structured, with a special focus on overall experience/attitude towards the courses, assessment and studentmentor relationship. To recruit students to interview, we asked mentors to list students that they thought had different opinions about the course; negative, positive or mixed/changed over time. Then we selected students, at least two from each year, from different mentor groups from each of the three courses, that was as heterogeneous as possible. For PIC3 students, we also took into account if they were international students, and if they enrolled in a PIC during their first cycle studies. In total, eight students from PIC1, seven students from PIC2, and seven students from PIC3 were interviewed. For the mentors, all mentors that answered the questionnaire were invited to also express their interest in participating in an interview. Two mentors from each course were chosen to be interviewed, six in total, none of them are authors of this paper. Each interview lasted approximately half an hour. The interviews were analyzed using thematic analysis [3] for each of the three questions studied. A thematic analysis is an inductive approach that is used to interpret data by identifying themes and was conducted according to six steps described by Braun and Clarke [4]. The thematic analysis has been carried out by the first author and the identified themes verified by the other authors.

In PIC2 and PIC3, anonymous course questionnaires are mandatory to answer for all students. The answers cannot be traced back to individual students and have no impact on the students' grades. Students could also choose to have their anonymous answers excluded from the research study. We used a 7 point Likert scale, ranging from 1. No, I strongly disagree with the statement to 7. Yes, I strongly agree with the statement. The questionnaires were sent out at the end of the academic year, in both 2017 and 2018. In PIC1, the students are not required to participate in a course questionnaire, and therefore no PIC1 students were part of the questionnaire data collection. A questionnaire was also sent out to all mentors in each of the three courses, end of spring semester 2018, containing both 7 point Likert scale questions and open questions.

\section{RESULTS}

Out of the 25 mentors (out of which six are mentors in two of the courses), 22 answered the questionnaire (88\%). Since the questionnaires for PIC2 and PIC3 are mandatory, all students that participated in these courses answered the questionnaires, however, 5 percent in 2017 and 7 percent in 2018 choose to not be part of the study and their answers were of course excluded. In total 950 remaining responses came in from the PIC2 questionnaires 2017 and 2018, but in that number most students that were in year 1 and 22017 also answered the questionnaire in 2018, possibly answering differently. The total unique students who took part in the questionnaires were 630. For PIC3, 590 responses were registered, and the unique students who took part in the questionnaires were 470. The thematic analysis of the interview data resulted in seven themes. The results from both interviews and questionnaires are presented under each of the three questions addressed, where the found themes from the thematic analysis are subheadings and some example quotes are presented.

\section{Which Is the Perceived Purpose?}

In general, the students stated that they are aware of the purposes of the seminars and the whole course. The third year students of PIC2 and all PIC3 students evaluated the statement $I$ know the purpose of the programme integrating course in 2017 $(\mathrm{n}=446)$ and $I$ understand the aims of the seminars and activities of the programme integrating course in $2018(n=450)$, see Figure 1. The PIC2 questionnaire also confirms that PIC2 students think that it has been interesting and fruitful to listen to students from other grades at the seminars $(\mathrm{n}=947)$, also shown in Figure 1 . The statement Overall, the programme integrating course has been fruitful was evaluated in the questionnaires of both PIC2 and PIC3 in 2017 and 2018. Figure 2 presents the result for each grade.

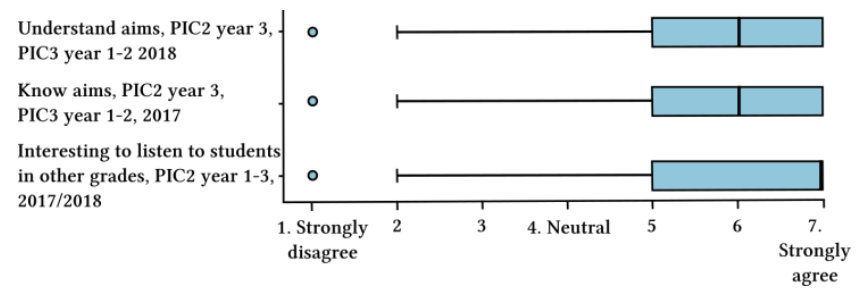

Figure 1: Questionnaire answers to the statement regarding aims and discussions across grades.

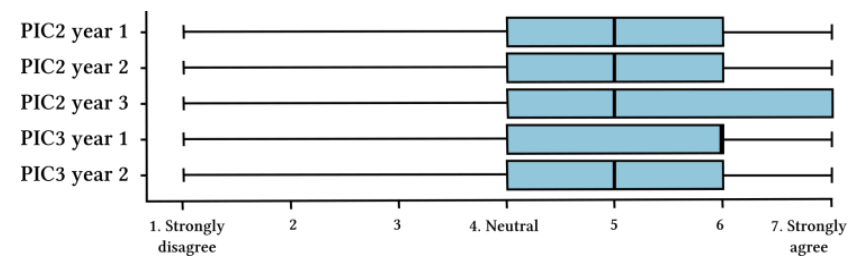

Figure 2: Questionnaire answers to the statement "Overall, the PIC course has been fruitful".

\subsection{Sharing Experience - Evoking Change}

All interviewed students, even those disliking the course, enjoyed getting to know other students and sharing their experiences. It was described as both creating a sense of not being alone in struggling with courses and also a way to get useful information from older students. This was particularly valuable for students who transferred and first year students enrolled in PIC1 or PIC2. 
Discussing the programmes' courses and how they link to each other, was described to be an important part of the PICs, where the mentors were seen as gateways to change things, even though students and mentors felt like not all complaints were brought to the responsible person or dealt with. That this channel was somewhat missing was also stated as something that could be improved in the courses by several of the mentors in the openended question of their questionnaire. The mentors in PIC2 have an informal meeting in connection with each round of seminars, something PIC1's and PIC3's mentors described as missing.

"You get the opportunity to see what you should focus on during the education. Talking to people who are in the grades above, who know more. "- PIC1 student year 3

\subsection{Not My Subject}

Not all students saw value in discussing topics that were nontechnical and experienced to be far from what they choose to study. This opinion was common among the interviewed CSmajors, but also found among some of PIC1's students. The mentors also describe that students' attitudes towards some topics could be disappointing. It could be frustrating for the mentors who experienced that they did not succeed in getting across the importance of these non-technical topics. Some mentor also expressed that discussing these topics could be out of their own comfort zone. The courses were, however, described to fill in gaps in the learning objectives of the programme, by both students and mentors. Some students did also see the course as an opportunity to reflect about questions they might not otherwise have time for and it could be a positive break from all the regular courses. The number of students who do not think a topic is fruitful, differs between the topics, but is always a clear minority, see Table 2, showing the proportion of the PIC2 students in year 12017 and year 22018 answering below 4 in the Likert scale on the statement I think that the topic $X$ was fruitful.

Table 2. The proportion of students negative to the fruitfulness of the first 8 topics of PIC2

\begin{tabular}{|l|l|}
\hline Topic & $\begin{array}{l}\text { Percentage } \\
\text { that scored } \\
\text { below 4 }\end{array}$ \\
\hline Study motivation and study techniques & $14 \%$ \\
\hline Learning objectives, criteria and assessment & $28 \%$ \\
\hline Plagiarism and my own responsibility & $22 \%$ \\
\hline My future role as computer science engineer & $13 \%$ \\
\hline Masters programmes & $8 \%$ \\
\hline Study and work abroad & $15 \%$ \\
\hline Minorities and equal treatment & $23 \%$ \\
\hline Quality in education - what is that? & $16 \%$ \\
\hline
\end{tabular}

"It's not so much about technology, but it's more about other things that aren't really so interesting. Like, how do you learn to program from this?"- PIC2 student year 1

\section{How Is the Assessment Perceived?}

In the questionnaires, five questions regarding the assessment were asked, showed in Figure 3. In general, the students from PIC2 and PIC3 agreed that assessment of the reflections was correctly done by their mentor. But, when asked about how the reflections were assessed in other groups, the answers were more neutral. PIC3 students were sceptical towards using a grading scale and the PIC2 students had different opinions regarding if their two-level scale was motivating, resulting in a natural median.

\subsection{Easy to Pass, but What Are We Graded On?}

All students seem to know that it is important to hand in the reflection documents on time, but other than that, the interviewed students did not know much about the grading systems used, what they were assessed on or based on which criteria. Some students felt a bit unsure if their mentor actually read their texts and expected full marks as long as they handed in their reflection document on time. The students from PIC1 and PIC3 had a hard time picturing how you could grade the reflection documents, since they are personal opinions. The interviewed PIC3 students that had enrolled in PIC2, did see that having the reflections graded in two levels had a point because they experience that they, themselves, and their peers were more serious about the assignments and therefore wrote better reflections. However, just grading the assignments pass/fail was thought to contribute to everyone actually expressing their opinion, rather than trying to write what they thought the mentor wanted to read.

"I think it is good that only pass/fail is used, because otherwise people would probably stress about it and try to write more formally, not what they actually think." -PIC1 student year 2

To the question How do you experience the assessment of the students' reflections?, the majority of the mentors were indifferent or stated it was more easy/clear than difficult/unclear, see Figure 4 $(\mathrm{n}=16,6$ declined to answer). The interviewed mentors did however, described the assessment as the trickiest part, not necessarily something they were used to do. The interviewed mentors did also confirm the students' picture that they do not always have the time to read through all the texts properly. In PIC1 and PIC3, the mentors should also assess the quality of the students' comments on each other's reflections (that comments were not just statements like "I agree"), which were sometimes overlooked. 


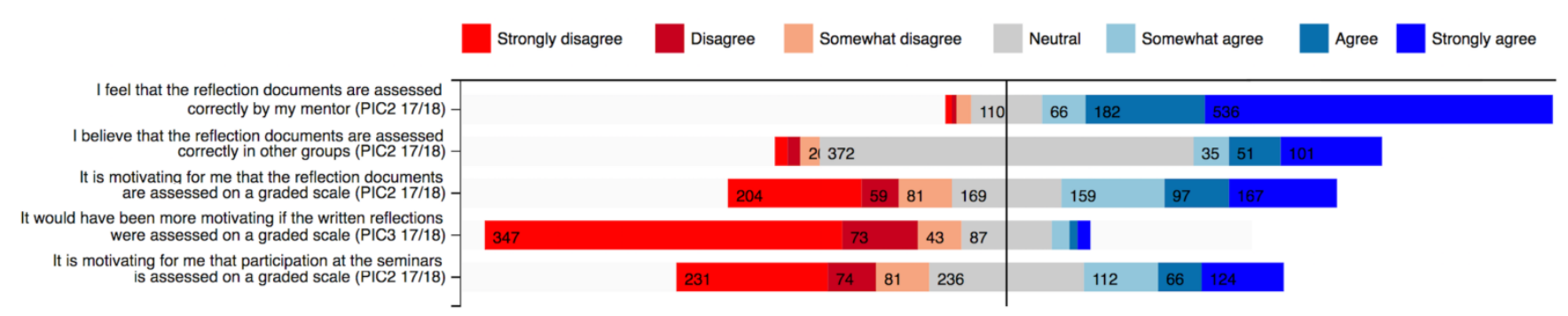

Figure 3: Questionnaire answers to statements regarding assessment in PIC2 and PIC3.

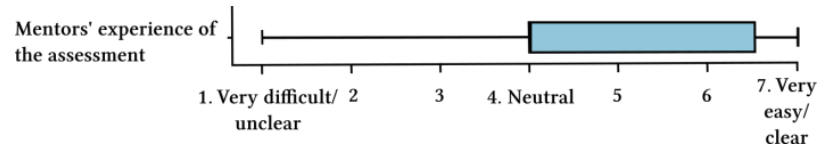

Figure 4: Mentors' questionnaire answers to how they experience the assessments.

\subsection{Judged by Peers - Could Be Too Personal}

The topics discussed were sometimes experienced as too personal, which made some students uncomfortable sharing their thoughts and opinions. Fearing their texts might be shared outside class. Some students expressed to be uncomfortable by the informal "judgments" and tried to adapt their texts towards the general opinion of the group. This peer-review system was also brought up by the mentors and thought to give the students more motivation to write better reflections. However, the mentors could also feel that they were intruding on their students' personal space by reading and commenting on their reflections.

"I didn't like PIC1 much at all. I had a hard time writing, reaching the word limit, because I didn't like to share personal information. Also, you post it, you give other people access to it. You do not know what will happen to that text." - PIC3 student year 2, that have also enrolled in PIC1

\subsection{Bad Timing - Not Priority}

In the interviews, some of students expressed that the timing of these reflections always was the worst possible; when all the other courses had assignments due. Students' from all courses described how that made them rush through these assignments, and they were not prioritized. The reason given for this prioritization was explained by the fact that it was not a high stake assessment and viewed as easy to pass/get full credit on. The mentors did also express that some students rushed their reflections, and did themselves also experience that timing could be far from perfect. Lack of time could, as mentioned above, result in not having the time to read through all documents, or having any time to write feedback. But not all mentors saw the grading or their involvement as something important, the more important part was thought to be that the students did reflect and attended the seminars.

"Everyone has lot of other courses they are doing, too many deadlines, too many assignments. So, we mostly concentrate on them and we usually forget about this." - PIC3 international student year 2

\section{How Is the Relationships Perceived?}

No specific question regarding the relationships between students, or students and mentors were asked in the questionnaires. The themes presented below are from the thematic analysis of the interviews, but also verified by mentors' answers to open questions on their questionnaire.

\subsection{Knowing Each Other by Name}

Experienced mentors expressed to be fortunate to follow the development of their students throughout the years. To be able to know their names, which might not be possible in other courses with large number of students. The mentors expressed to be proud of the students that expressed well-phrased opinions, but a bit disappointed by those students who showed that they would have preferred to not enroll in the course.

"Sometimes, the regular courses I teach has more than 250 students so there I often do not get the chance to get to know individuals. [...] It is nice to see how they develop and if I don't know who is who, then it's hard to." - mentor PIC 3

The students described their relationships to the mentor to be much depending on the mentor. If the mentor showed interest, listen and shared their own opinions, it was experienced as good relationship. It could then, extend to be a mentorship outside the course, a person to which you could turn to with any study related issues, almost like a mentor from high school. The students who felt their mentors did not seem to care so much or to be there only because they had to, would, understandably, not seek their mentors outside class. Some students even expressed a disappointment that they had not got to know the mentor, as they expected.

\subsection{Personality and Engagement}

Both mentors and students described the personality of the students to influence the seminars. Some students are talkative and some are shy. Both students and mentors described how they tried to get these shy members of the group to also participate, although that was not always possible. The level of engagement in the course, from both students and mentors, was also described to influence the experience of the course, and the students that felt their mentors or fellow group members did not seem to care were, understandably, not that interested in the course either. A couple of the mentors did also express as comments in the questionnaire, 
that they had been assign to be a mentor, not given the choice to become one. The student-student relationship, were, as stated in the theme "Sharing Experience - Evoking Change", viewed as an important part of the course and much appreciated.

"In PIC3, it has generally felt like all teachers and all students, thinks 'this is just something we have to do. We just have to get through this'"- PIC3 student year 1

\section{DISCUSSION AND CONCLUSIONS}

We have performed an interview and questionnaire study to gain a deeper understanding of how students and mentors experience PICs. The students are generally positive, stating to understand the aims and find it rewarding to hear the opinion of others. However, there is room for improvement as not all students experience the courses as "fruitful". We could also see a difference between the grades, where year 3 students ranked the "fruitfulness" higher than year 1 and year 2 students.

The interviewed students all expressed that sharing experience that could evoke change, was the main benefit of the course. The mentors, and some students, were however, not entirely satisfied with how this feedback given to the mentors was dealt with. The feedback channel could be further improved and, as suggested by the mentors, become more structured. After this study, changes have been implemented in PIC1, so that all unfiltered reflections regarding courses are also sent to the responsible teacher, if permitted by the student.

Writing a reflection and discussing a given topic, received mixed reviews by the interviewees and was perceived as unnecessary by some. The results from the interviews could point towards that these more sceptical students fail to see how these assignments aligns with what they perceived to be the purpose of the course, the sharing of experiences. However, the learning objectives are an integrated part of the topics in the PICs. It is therefore more likely that these students simply do not agree with all learning objectives and do not see a point in fulfilling them. Hence, this particular group of students, could be put in contrast with previous findings [7], that showed that the students collectively have the same view as the programme coordinator of which competences the education programme should develop. Reflecting on non-technical topics seems to be out of some of the students' comfort zone and the level of engagement differs. A (better) motivation why these topics are important, beyond the learning outcomes, might assist this. In some cases, the topics are personal, which of course adds to the discomfort. One way to reduce this could be to formulate topic-related alternatives in such a way that the students are not required to share personal information.

The students felt that the assessment of the reflections was correctly done by their mentor. But interestingly, when asked about the assessment in other groups, the answers were quite different. The main difference was that instead of answering "strongly agree", the students either answered "neutral" or declined to answer. An explanation could be that the students are not aware of the quality of the assessment in other groups, which we did not anticipate, but in retrospect it seems natural. We could also see a similar trend in the mentors' questionnaire answers (large number declined to answer this question), indicating that not all mentors have reflected about the assessment.

The question regarding if the present grading scale in PIC2 (pass/pass with distinction) is motivating, divides the students: about the same number of students are negative and positive - the median is "neutral". The students from PIC3 that only have one passing grade do, however, unite in the opinion that more levels would be negative. Perhaps information on why each scale is used could increase the understanding and reminders on how the grading is done could possibly reduce the uncertainty about what is graded for students and mentors.

The mentor-student relation, growing over the years, are appreciated by both sides, but not all mentors seem to be engaged to the same extent in the course and engagement is important [1]. For the PICs it might be even more important to recruit mentors who are interested in these kinds of social relationships with the students. Further strengthening of the collaboration and discussion among the mentors, described as somewhat missing in PIC1 and PIC3, could possibly make the mentors a bit more engaged.

Since these seminars occur only four times per year, they appear as a regular surprise, always with a bad timing for some. Considering the workload of the students, it is doubtful whether there are any good time slots. One remedy could be to add a weekly time slot in the schedule for the students to work on their reflection, or at least as a reminder that they ought to do that.

From these results, it is apparent that the mentors are engaging in different ways, with varying results among the students. Future research of PICs should aim at identifying and spreading best practices among the mentors.

\section{REFERENCES}

[1] K. Bain. What the Best College Teachers Do. Cambridge: Harvard University Press. 2011.

[2] J. Biggs. Teaching for Quality Learning at University - What the Student Does 2nd Edition SRHE / Open University Press, Buckingham, 2003.

[3] R.E. Boyatzis. Transforming qualitative information: thematic analysis and code development. CA: SAGE publications, 1998.

[4] V. Braun and V. Clarke. Using thematic analysis in psychology. Qualitative Research in Psychology, vol. 3, no. 2, pp. 77-101, 2006.

[5] O. Bälter, B. Hedin, T. Helena, \& S. Toivanen. Walking Outdoors during Seminars Improved Perceived Seminar Quality and Sense of Well-Being among Participants. International Journal of Environmental Research and Public Health, 15(303), 2018.

[6] C. Conrad and R. Serlin. The Sage handbook for research in education: Pursuing ideas as the keystone of exemplary inquiry (2nd ed.). Thousand Oaks, Calif.: SAGE Publications. 2011.

[7] S. Frezza et al. Modelling competencies for computing education beyond 2020: a research based approach to defining competencies in the computing disciplines. ITiCSE 2018 Companion Proceedings Companion of the 23rd Annual ACM Conference on Innovation and Technology in Computer Science Education. Pages 148-174, 2018.

[8] G. Hagenauer and S. Volet. Teacher-student relationship at university: An important yet under-researched field. Oxford Review of Education, 40(3), 370-388, 2014.

[9] N. Hatton and D. Smith. Reflection in teacher education: Towards definition and implementation. Teaching and teacher education, 11(1):33-49, 1995.

[10] B. Hedin. Program integrating course: A tool for reflection and quality management. In Proc. 2:nd Development Conference for Sweden's Engineering Programs, 2009.

[11] B. Hedin and V. Kann, Improving Study Skills by Combining a Study Skill Module and Repeated Reflection Seminars, Education Research International, vol. 2019, Article ID 9739854, 8 pages, 2019. https://doi.org/10.1155/2019/9739854.

[12] F. Heintz, A. Berglund, B. Hedin, V. Kann. A comparison between program integrating courses at KTH and Linköping University (in Swedish). In Proceedings of 5:th Development Conference for Sweden's Engineering Programs, 2015. 
[13] V. Kann. A program integrating course with many functions (in Swedish). In Proceedings of the 3:rd Development Conference for Sweden's Engineering Programs, pages 153-156, 2011.

[14] V. Kann and A.-K. Högfeldt. Effects of a Program Integrating Course for Students of Computer Science and Engineering. In Proceedings of the 47th ACM Technical Symposium on Computing Science Education (SIGCSE '16). ACM, Memphis, Tennessee, USA, 510-515, 2016.

[15] V. Kann and M. Magnell. Reflektionsseminarier som håller ihop och utvecklar programmet (in Swedish). In Proceedings of the 4:th Development Conference for Sweden's Engineering Programs, Umeå University. 2013.

[16] A. Y. Kolb and D. A. Kolb. The learning way meta-cognitive aspects of experiential learning. Simulation \& Gaming, 40(3):297-327, 2009.
[17] S. Lähteenoja and A.-M. Pirttilä Backman. Cultivation or coddling? University teachers' views on student integration. Studies in Higher Education, 30, 641-661, 2005.

[18] S. Nilsson. On the meaning of higher education in professional practice: the case of physicians and engineers. Journal of Education and Work, 23(3):255-274, 2010.

[19] L. Strauss and J. Volkwein. Predictors of Student Commitment at Two-Year and Four-Year Institutions. The Journal of Higher Education, 75(2), 203-227, 2004.

[20] V. Tinto. Dropout from higher education: a theoretical synthesis of recent research. Review of Higher Education, 45, 89-125, 1975.

[21] B. J. Zimmerman. Self-regulated learning and academic achievement: An overview. Educational psychologist, 25(1):3-17, 1990. 